\title{
Effectiveness of twice daily azelastine nasal spray in patients with seasonal allergic rhinitis
}

\author{
Friedrich Horak \\ Medical University Vienna, \\ ENT - Univ. Clinic, Vienna, Austria
}

\begin{abstract}
Azelastine nasal spray (Allergodil ${ }^{\circledR}$, Lastin $^{\circledR}$, Afluon ${ }^{\circledR} ;$ Meda AB, Stockholm, Sweden) is a fast-acting, efficacious and well-tolerated H1-receptor antagonist for the treatment of rhinitis. In addition it also has mast-cell stabilizing and anti-inflammatory properties, reducing the concentration of leukotrienes, kinins and platelet activating factor in vitro and in vivo, as well as inflammatory cell migration in rhinitis patients. Well-controlled studies in patients with seasonal allergic rhinitis (SAR), perennial rhinitis (PR) or vasomotor rhinitis (VMR) confirm that azelastine nasal spray has a rapid onset of action, and improves nasal symptoms associated with rhinitis such as nasal congestion and post-nasal drip. Azelastine nasal spray is effective at the lower dose of 1 spray as well at a dose of 2 sprays per nostril twice daily, but with an improved tolerability profile compared to the 2 -spray per nostril twice daily regimen. Compared with intranasal corticosteroids, azelastine nasal spray has a faster onset of action and a better safety profile, showing at least comparable efficacy with fluticasone propionate (Flonase ${ }^{\circledR}$; GSK, USA), and a superior efficacy to mometasone furoate (Nasonex ${ }^{\circledR}$; Schering Plough, USA). In combination with fluticasone propionate, azelastine nasal spray exhibits greater efficacy than either agent used alone, and this combination may provide benefit for patients with difficult to treat seasonal allergic rhinitis. In addition, azelastine nasal spray can be used on an as-needed basis without compromising clinical efficacy. Compared with oral antihistamines, azelastine nasal spray also demonstrates superior efficacy and a more rapid onset of action, and is effective even in patients who did not respond to previous oral antihistamine therapy. Unlike most oral antihistamines, azelastine nasal spray is effective in alleviating nasal congestion, a particularly bothersome symptom for rhinitis sufferers. Azelastine nasal spray is well tolerated in both adults and children with allergic rhinitis. Bitter taste which seems to be associated with incorrect dosing technique is the most common side effect reported by patients, but this problem can be minimized by correct dosing technique.
\end{abstract}

Keywords: azelastine nasal spray, rhinitis, intranasal corticosteroids, oral antihistamines, seasonal allergic rhinitis

\section{Introduction}

Rhinitis is an inflammatory disease of the upper airways, affecting approximately 58 million people only in the United States alone (Settipane 2001) and its prevalence is increasing. The cost of the disease is significant with between US\$2 and US $\$ 5$ billion incurred annually in both direct and indirect costs (Ray et al 1999; Reed et al 2004). In the US, the number of lost workdays is estimated as approximately 3.5 million a year (Mahr and Sheth 2005). It can be classified as allergic, non-allergic or mixed upper respiratory disorder (Berstein 2007). It is classified as allergic if symptoms occur in association with a specific IgE-mediated response; as non-allergic if symptoms are induced by irritant triggers, but without an IgE-mediated response; and as of mixed etiology if IgE-mediated responses occur in conjunction with symptoms induced by both allergens and non-allergic irritant triggers. Allergic rhinitis (AR) is further classified as seasonal or perennial (Dykewicz et al 1998). Seasonal allergic rhinitis 
(SAR) symptoms are induced by exposure to pollens from trees, grass, weeds or seasonal mould spores, whilst perennial rhinitis (PR) is associated with environmental allergens which are generally present on a year-round basis such as house dust, animal dander and insect droppings (Dykewicz et al 1998). In contrast, the "Allergic Rhinitis and its Impact on Asthma (ARIA) guidelines" recommend a classification in intermittent allergic rhinitis and persistent allergic rhinitis according to the frequency and persistence of symptoms (Bousquet et al 2001).

Symptoms of SAR include nasal congestion, runny nose, nasal and nasopharyngeal itching, ear symptoms, sneezing and ocular symptoms in many patients, including itchy and watery eyes (Bielory and Ambrosio 2002). The symptoms of sneezing, itching and rhinorrhea are less common with PR (Economides and Kaliner 2002). As many as half of all patients diagnosed with rhinitis have non-allergic disease (sometimes called vasomotor rhinitis [VMR]) where an allergic component cannot be identified (Dykewicz et al 1998). Symptoms are often induced by irritant triggers such as tobacco smoke, strong odors and temperature and pressure changes (Devyani and Corey 2004). The symptoms of VMR are similar to those of AR (Devyani and Corey 2004). To further complicate rhinitis classification, as many as half of all patients with AR are also sensitive to non-allergic triggers; a condition referred to as mixed rhinitis (Settipane and Settipane 2002; Liberman et al 2005). Symptoms of rhinitis can have a major impact on patients' quality of life (QoL) by interfering with sleep which causes fatigue, and impairing daily activities and cognitive function (Dykewicz et al 1998). Patients often complain of an inability to concentrate, and in the case of SAR often avoid outdoor activities in order to avoid exposure to symptom-inducing allergen(s). The Joint Task Force on Allergy Practice and Parameters advises that improving the negative impact on daily life in rhinitis patients defines successful treatment as much as providing symptom relief (Dykewicz et al 1998). Indeed, Juniper (1997) recommends that for most patients with rhinitis, improving patient well-being and QoL should be the primary goal of treatment.

Treatment guidelines from the Joint Task Force and WHO recommend that antihistamines, both topical (eg, azelastine [Allergodil ${ }^{\circledR}$; Meda AB, Stockholm, Sweden]) and oral second-generation (eg, loratadine [Claritin ${ }^{\circledR}$, Schering Plough, USA], desloratadine [Clarinex ${ }^{\circledR}$; Schering Plough, USA], fexofenadine [Allegra ${ }^{\circledR}$; Sanofi Aventis, USA] or cetirizine [Zyrtec $^{\circledR}$; Pfizer, USA], and levocetirizine $\left[\right.$ Xyzall $^{\circledR}$; UCB, EU]) be used as first-line therapy for AR (Dykewicz et al 1998;
Bousquet et al 2001). Intranasal corticosteroids (eg, fluticasone propionate [Flonase ${ }^{\circledR}$, GSK, USA], mometasone furoate [Nasonex ${ }^{\circledR}$; Schering Plough, USA]) may also be considered as initial therapy for AR in patients with more severe symptoms, particularly nasal congestion [(Dykewicz et al 1998; LaForce 1999). The Allergic Rhinitis and its Impact on Asthma (ARIA) guidelines recommend a stepped approach to therapy based upon the frequency and severity of symptoms (Table 1) (Bousquet et al 2001). Interestingly, a recent US nationwide survey incorporating approximately 2500 adult allergy sufferers, revealed that $66 \%$ were dissatisfied with their current allergy medication due to lack of effectiveness (Anon 2006). Furthermore, more than two-thirds of primary care physicians reported patient dissatisfaction with therapy as the main reason for stopping or switching medications (Anon 2001). Clearly, effective therapies with a good safety profile are needed to treat AR sufferers.

\section{Azelastine}

Azelastine nasal spray is a topically administered secondgeneration antihistamine and selectively antagonizes the $\mathrm{H}_{1}$-receptor (Zechel et al 1981) being approximately tenfold more potent than chlorpheniramine in this regard (Casale 1989). It has one of the fastest onsets of action (15 min with nasal spray and up to 3 min with eye drops) among the currently available rhinitis medications (Baumgarten et al 1994; Greiff et al 1997). The effect of azelastine lasts at least 12 hours, thus allowing for a once or twice daily dosing regimen (Greiff et al 1997). It has proven efficacy in treating both allergic and non-allergic rhinitis, and is the only prescription antihistamine approved in the US, Portugal and the Netherlands for the treatment of both SAR (1996) and VMR (1999). In SAR patients azelastine therapy (two sprays per nostril twice daily), improved both total symptom and major symptom complex scores to a significantly greater extent than placebo (McTavish and Sorkin 1989; Storms et al 1994; LaForce et al 1996; Ratner and Sacks 2007). Similarly, in PR patients, azelastine nasal spray significantly improved sleeping, reduced daytime somnolence and nasal congestion compared with placebo (Golden et al 2000). Liberman et al (2005) were the first to show that azelastine was also effective in the management of VMR and even in mixed rhinitis. Azelastine nasal spray significantly $(\mathrm{p}<0.01)$ reduced the total VMR symptom score (TVRSS) compared with placebo after 21-day double-blind treatment, and was associated with clinical improvement in each symptom of the TVRSS (ie, rhinorrhea, sneezing, nasal congestion, and post-nasal drip). In a large open-label trial 4364 patients received azelastine nasal spray 
Table I Summary of ARIA allergic rhinitis management guidelines

\begin{tabular}{|c|c|}
\hline Rhinitis severity & ARIA recommendation \\
\hline Mild intermittent & $\begin{array}{l}\text { - Oral/intranasal antihistamines OR } \\
\text { - Decongestants ( } 10 \text { days maximum) }\end{array}$ \\
\hline Moderate/severe intermittent & $\begin{array}{l}\text { - Intranasal antihistamines } \\
\text { - Oral antihistamines AND/OR } \\
\text { - Decongestants } \\
\text { - Intranasal corticosteroids } \\
\text { - Cromones }\end{array}$ \\
\hline Mild persistent & $\begin{array}{l}\text { - Intranasal antihistamines } \\
\text { - Oral antihistamines AND/OR } \\
\text { - Intranasal corticosteroids } \\
\text { - Cromones } \\
\text { A stepwise approach is advised with reassessment after } 2 \text { weeks. If symptoms } \\
\text { are controlled and the patient is on intranasal corticosteroid, the dose should } \\
\text { be reduced, but otherwise treatment continued. If symptoms persist and the } \\
\text { patient is on antihistamines or cromones, a change should be made to an } \\
\text { intranasal corticosteroid. }\end{array}$ \\
\hline Moderate/severe persistent & $\begin{array}{l}\text { - Intranasal corticosteroid (first line treatment) } \\
\text { If symptoms are uncontrolled after } 2-4 \text { weeks, medication should be added } \\
\text { depending on the persistent symptom, eg, add an antihistamine if the major } \\
\text { symptom is rhinorrhea, pruitis, or sneezing, double the dose of intranasal } \\
\text { steroid for persistent nasal blockage and add ipratropium for prominent } \\
\text { complaint of rhinorrhea. }\end{array}$ \\
\hline
\end{tabular}

( 2 sprays per nostril twice daily) as monotherapy for 2 weeks. $78 \%$ of VMR patients reported some or complete control of post-nasal drip which rose to $90 \%$ of SAR patients for the symptom of sneezing. Of patients reporting sleep difficulties or impaired daytime activities because of rhinitis symptoms, $85 \%$ experienced improvements in these parameters with azelastine. Baseline sleep difficulties and impairment of daytime activities were significant $(p<0.01)$ predictors of a positive treatment effect with azelastine nasal spray. Female patients $(\mathrm{p}=0.02)$, patients with SAR $(\mathrm{p}<0.01)$ and patients with SAR plus sensitivity to non-allergic triggers $(p=0.03)$ were identified as being most likely to respond to azelastine nasal spray (Liberman et al 2005) Due to its rapid onset of action, azelastine nasal spray continues to control rhinitis symptoms when used on an as-needed basis (Ciprandi et al 1997). This property of azelastine is discussed later. First marketed in the UK in 1991 for the treatment of both SAR and PR, it is currently available in more than 70 countries world-wide.

\section{Mode of action}

However, azelastine is more than just an anti-histamine. It exhibits a very fast and long-acting effect based on a triple mode of action, with anti-inflammatory and mast cell stabilizing properties in addition to its anti-allergic effects (Bernstein 2007; Lee and Corren 2007). For example, azelastine inhibits the activation of cultured mast cells and release of interleukin (IL)-6, tryptase, and histamine (Kempuraj et al 2002). It also reduces mediators of mast cell degranulation such as leukotrienes which are involved in the late phase allergic response (Howarth 1997), in the nasal lavage fluid of patients with rhinitis (Shin et al 1992). It does this possibly by reducing the production of leukotriene (LT)B and $\mathrm{LTC}_{4}$, inhibiting phospholipase $\mathrm{A}_{2}$ and $\mathrm{LTC}_{4}$ synthase (Hamasaki et al 1996). Leukotrienes are associated with dilation of vessels, increased vascular permeability and edema which results in nasal congestion, mucus production and recruitment of inflammatory cells (Golden et al 2006). Substance $P$ and bradykinin concentrations which are formed in biological fluids and tissues during inflammation, are also reduced by azelastine (Shin et al 1992; Nieber et al 1993; Shinoda et al 1997). These agents are associated with the AR symptoms of nasal itching and sneezing, but may also contribute to the onset of non-allergic VMR symptoms. Other anti-inflammatory properties of azelastine include inhibition of tumor necrosis factor alpha (TNF $\alpha)$ release 
(Hide et al 1997; Matsuo and Takayama 1998), reduction of granulocyte macrophage colony-stimulating factor (GM-CSF) generation, as well as a reduction in the number of a range of inflammatory cytokines including interleukin (IL)-1 $\beta$, IL-6, IL-4 and IL-8 (Yoneda et al 1997; Ito et al 1998; Beck et al 2000). These cytokines perpetuate the inflammatory response (Settipane 2001). Finally, in SAR patients, azelastine nasal spray has been shown to lower neutrophil and eosinophil counts and decrease intercellular adhesion molecule-1 (ICAM-1) expression on nasal epithelial cell surfaces in both the early and late phases of the allergic reaction (Ciprandi et al 1996). It also decreases free-radical production by human eosinophils and neutrophils (Busse et al 1989; Umeki 1992) and calcium influx induced by platelet-activating factor in vitro (Nakamura et al 1988; Morita et al 1993).

The use of a topical treatment has many advantages over a systemic treatment. Firstly, with a nasal spray, medication can be delivered directly to the site of allergic inflammation. Secondly, the higher concentrations of antihistamines that can be achieved in the nasal mucosa by topical as opposed to oral administration should enhance the anti-allergic and potential anti-inflammatory effects of these agents. Thirdly, a dose of $0.28 \mathrm{mg}$ intranasally has a faster onset of action than a dose of $2.2 \mathrm{mg}$ administrated orally (Horak et al 1994). And finally, with topical administration the risk of interaction with concomitant medication is minimized (Davies et al 1996) and the potential of systemic effects reduced.

\section{Dosage}

Recent results from 2 studies have shown that azelastine nasal spray at a dosage of 1 spray per nostril twice daily is effective and has a better tolerability profile compared to 2 sprays per nostril twice daily in patients ( $\geq 12$ years; $n=554$ ) with moderate to severe SAR (Lumry et al 2007). The total nasal symptom score (TNSS) improved by $14.1 \%$ in study 1 and by $22.1 \%$ in study 2 with azelastine nasal spray ( 1 spray per nostril twice daily) compared with $4.5 \%$ and $12.0 \%$ with placebo in study $1(\mathrm{p}=0.01)$ and $2(\mathrm{p}<0.01)$ respectively. This compares with a $24 \%-29 \%$ improvement in rhinitis symptoms scores with a 2-spray dosage of azelastine (Ratner et al 1994; Storms et al 1994; LaForce et al 1996). For individual symptoms, itchy nose, runny nose, sneezing, and nasal congestion were all significantly improved after the 1-spray azelastine regimen compared with placebo. One spray per nostril twice daily of azelastine was also associated with significant improvements in the Rhinitis Quality of Life Questionnaire (RQLQ) daily activity and nasal symptoms domains and patient global evaluations compared with placebo. In addition, the incidence of a bitter taste after azelastine application more than halved and the incidence of somnolence decreased almost 30 times in the 1-spray group versus the labeled incidence with the 2-spray regimen (Lumry et al 2007). Although an earlier study showed an improvement in rhinitis symptoms versus placebo with azelastine 1 spray per nostril twice daily, this improvement failed to reach statistical significance. However, a global evaluation noted a significant clinical improvement versus placebo $(49 \%)$ in the 1 -spray regimen $(75 \%, p<0.001)$ as well as a 2-spray once daily $(89 \%, \mathrm{p}=0.028)$ and a 2-spray twice daily regimen $(83 \%, \mathrm{p}<0.001)$ (Weiler et al 1994).

From these results one can conclude that a greater degree of effectiveness would be expected with two sprays per nostril twice daily. Although one spray per nostril twice daily may provide somewhat less efficacy this is compensated for by an improved tolerability profile compared with the 2-spray regimen. Therefore, the choice of dosage of azelastine nasal spray should be based on the severity and persistence of symptoms as well as the patient's acceptance of the nasal spray (Bernstein 2007). For example, the 2-spray dose could be used as the starting dose for patients with severe symptoms of SAR, and either maintained or tapered to the 1 -spray dose as required. The 1-spray dose could be used as a starting dose in patients with mild-to-moderate symptoms, and if necessary the dose increased to 2 sprays per nostril twice daily if symptom control proved to be inadequate (Lumry et al 2007).

\section{As-needed}

Because azelastine starts working within 15 minutes of application investigators wondered how effective an as-needed regimen would be in controlling the symptoms of rhinitis (Ciprandi et al 1997). A randomized controlled study was carried out in 30 patients sensitized to Parietaria pollen or grass. Patients were treated with the standard European dose of azelastine $(0.56 \mathrm{mg} /$ day $)$, half this dose $(0.22 \mathrm{mg} /$ day $)$, or as-needed. Both groups who received the standard and half-standard doses showed an improvement in their rhinitis symptoms, with a concomitant reduction in markers of inflammation, namely neutrophil and eosinophil counts as well as ICAM-1 expression in nasal scrapings. However, patients who used azelastine nasal spray on an as-needed basis also showed an improvement in their rhinitis symptoms, but without a reduction in the markers of inflammation. The results of this small study suggest that although regular treatment with azelastine is superior at controlling symptoms, as-needed therapy may be 
useful in the treatment of clinical symptoms (Ciprandi et al 1997). The use of azelastine nasal spray on an as-needed basis would be expected to improve drug tolerability and has important implications for patient compliance. Another option is to use azelastine as-needed in addition to an oral antihistamine treatment on days with severe symptoms of SAR.

\section{Comparisons with other agents used to treat rhinitis}

The complexity of rhinitis as a disease and the multiple pathways involved in its pathophysiology mean that there are several classes of drugs available to treat it. These include intranasal corticosteroids, oral antihistamines, intranasal antihistamines and mast-cell stabilizers (eg, cromolyn compounds). A useful metric to compare each of these treatment modalities is the number needed to treat (NNT), which estimates the number of patients who must be treated with a particular drug in order to have one positive outcome. Obviously, drugs with low a NNT are considered more effective than those with a higher NNT. One report estimated the NNT range for oral antihistamines as 9-35, 3-6 for intranasal corticosteroids, 5-6.3 for azelastine, and 4.6 for immunotherapy (Portnoy et al 2004). However, in that study the NNT was calculated using only a single trial for each drug, and so not all of the evidence was considered. A more recent meta-analysis systematically reviewed the efficacy of azelastine nasal spray, in terms of global assessment of efficacy, versus active comparators using NNTs as the outcome measure (Lee and Pickard 2007). The active comparators included beclomethasone (Beconase ${ }^{\circledR}$; GSK, USA) and budesonide nasal sprays (Rhinocort ${ }^{\circledR}$; Astra Zeneca, USA), loratadine, terfenadine (Seldane ${ }^{\circledR}$; Sanofi Aventis, USA), cetirizine, ebastine $\left(\right.$ Kestine $\left.^{\circledR}\right)$, and levocabastine. Forty-six studies were initially identified and 21 separate publications were included in the analysis. In 5 comparisons azelastine was more efficacious than placebo with a summary NNT of 5.0. No statistically significant difference was found between azelastine nasal spray and the other treatments, including intranasal corticosteroids, in terms of their efficacy in treating rhinitis. However, when the analysis was limited to studies in which an oral allergy treatment was the comparator, the point estimate of the pooled results favored azelastine nasal spray (Figure 1). The results were consistent across both SAR and nonallergic VMR, and across trials of different durations.

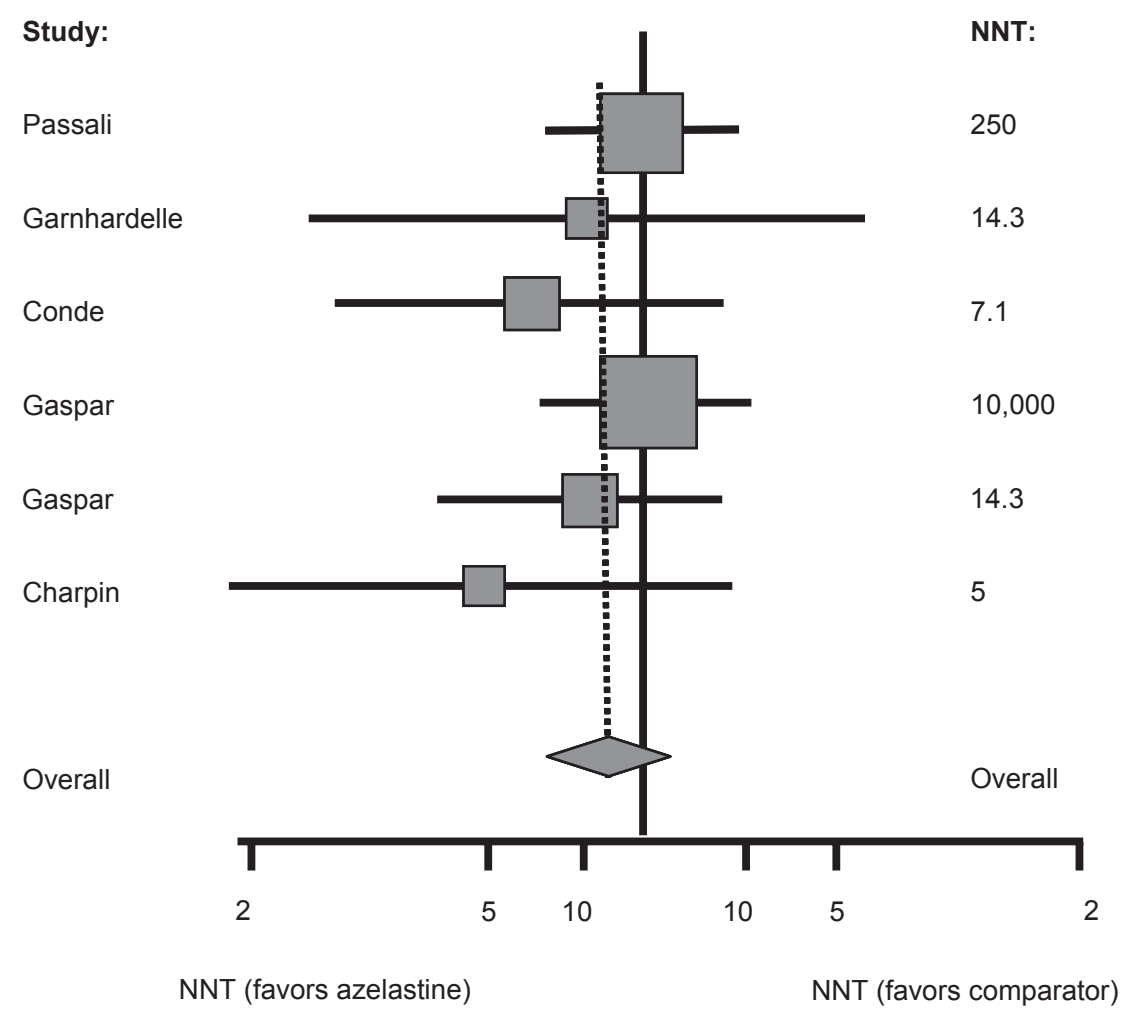

Figure I Number needed to treat a global assessment of efficacy as an outcome for azelastine nasal spray compared with oral agents for the treatment of allergic rhinitis. Reprinted with permission from Lee T,Pickard S. 2007. Meta-analysis of azelastine nasal spray for the treatment of allergic rhinitis. Pharmcotherapy, 27:852-9. Copyright @ 2007 Pharmcotherapy Publications.

Abbreviations: $\mathrm{Cl}$, confidence interval; NNT, number needed to treat.

Therapeutics and Clinical Risk Management 2008:4(5) 
The risk difference would have been even more favourable for azelastine if only results for azelastine at a dose of $1.12 \mathrm{mg} /$ day were included in the analysis, but the small number of studies available for the meta-analysis precluded that stratification (Lee and Pickard 2007).

\section{Comparisons with intranasal corticosteroids}

Azelastine nasal spray is a non-steroidal treatment and has some advantages over intranasal corticosteroids in the treatment of SAR, even though its anti-inflammatory effect is not as strong (Wang et al 1997). It has a faster onset of action compared with intranasal corticosteroids (Berkowitz et al 1999; Horak et al 2006), with at least comparable (in the case of intranasal fluticasone propionate) or superior (in the case of intranasal mometasone furoate) efficacy, and has a better safety profile (Behncke et al 2006; Patel et al 2007). Like intranasal corticosteroids, azelastine is effective in treating the symptom of nasal congestion. Whereas intranasal corticosteroid therapy should begin before the onset of symptoms in order to obtain optimal benefit from therapy antihistamines can also be taken on an as needed basis. But in contrast to intranasal corticosteroids azelastine may induce a bitter taste and nasal burning after application.

\section{Azelastine versus mometasone furoate}

Azelastine nasal spray is superior to the topical corticosteroid mometasone nasal spray in reducing nasal symptoms (Patel et al 2007). Patients with a history of SAR and symptomatic while exposed to ragweed pollen in an environmental exposure chamber (EEC) were randomized to 2 sprays per nostril of azelastine nasal spray (137 $\mu \mathrm{g} / \mathrm{spray} ; \mathrm{n}=150)$, mometasone nasal spray ( $50 \mu \mathrm{g} /$ spray; $\mathrm{n}=150)$, or placebo. At 15 minutes after administration of study drugs, azelastine nasal spray significantly reduced the TNSS from baseline by $29.5 \%$ compared with $12.3 \%$ with placebo $(\mathrm{p}<0.001)$ and this significant superiority of azelastine over placebo persisted at each time point throughout the 8-hour allergen exposure (Figure 2). At 8-hour post-allergen challenge, azelastine had reduced the TNSS by $33.9 \%$ from baseline versus $18.6 \%$ with placebo. Conversely, mometasone furoate nasal spray did not significantly reduce the TNSS from baseline compared with placebo at any time point ( $p \geq 0.09$ ), and azelastine nasal spray was significantly more effective than mometasone at each time point during the 8-hour study period ( $\mathrm{p} \leq 0.001$; Figure 2) (Patel et al 2007). A previously published study has shown a 12- to 72-hour onset of action for mometasone (Berkowitz et al 1999) which would explain why mometasone did not significantly improve

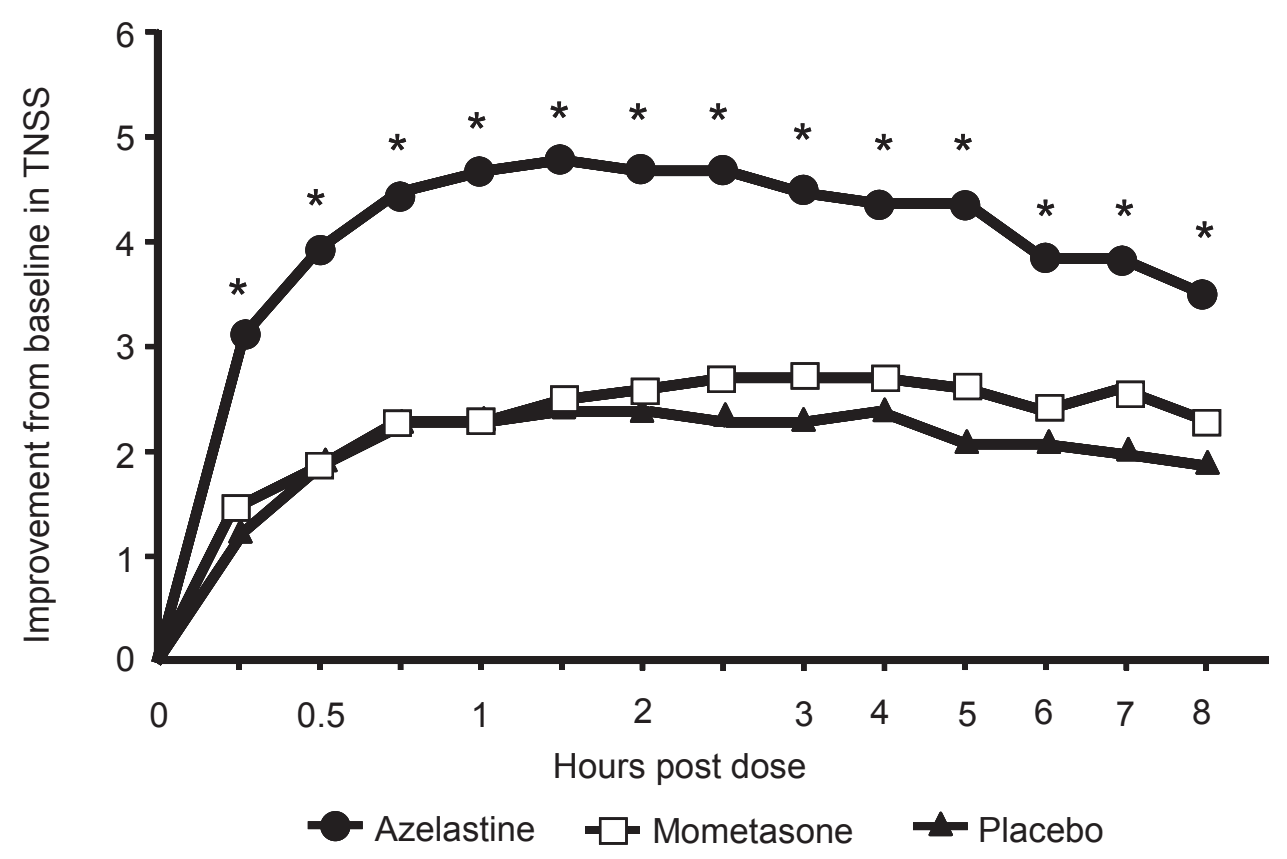

Figure 2 Onset of action of azelastine hydrochloride nasal spray in relieving nasal symptoms of seasonal allergic rhinitis. ${ }^{*} \mathrm{p}<0.00 \mathrm{I}$ azelastine vs placebo; ${ }^{*} \mathrm{p} \leq 0.00 \mathrm{I}$ azelastine vs mometasone; mometasone vs placebo $=$ not significant. Reprinted with permission from Patel P, D'Andrea C, Sacks HJ. 2007. Onset of action of azelastine nasal spray compared with mometasone nasal spray and placebo in subjects with seasonal allergic rhinitis evaluated in an environmental exposure chamber. Am J Rhinol, $21: 499-503$. Copyright () 2007 Oceanside Publications. 
SAR symptoms compared to placebo within 8 hours after allergen exposure. An online survey by the American College of Allergy, Asthma and Immunology showed that $77 \%$ of allergists and $69 \%$ of primary care physicians thought rapid onset of action was an essential element of therapy (Physician Survey 2001). A rapid onset of action within 15 minutes, as shown with azelastine nasal spray, may enhance compliance with therapy.

\section{Azelastine versus fluticasone propionate}

A study in geriatric patients with allergic or non-allergic rhinitis showed that azelastine nasal spray ( 2 sprays per nostril twice daily; $1.1 \mathrm{mg}$ ) was just as effective as fluticasone propionate nasal spray 2 sprays per nostril daily; $200 \mu \mathrm{g}$ ) at improving patients' RQLQ scores (Figure 3) and rhinitis symptoms (Figure 4) (Behncke et al 2006). Azelastine nasal spray and oral antihistamines are often used concurrently with an intranasal corticosteroid spray in patients with difficult to treat rhinitis symptoms. Several studies with oral antihistamines in combination with intranasal corticosteroids showed no increased clinical benefit with these drugs in combination (Weiner et al 1998; Nielsen and Dahl 2003). However, a recent proof-of-concept study showed that azelastine nasal spray and fluticasone nasal spray in combination provided a substantial therapeutic benefit for patients with SAR compared with therapy with either agent alone (Ratner and Sacks 2007). Patients were randomized to receive either azelastine nasal spray (2 sprays per nostril twice daily), fluticasone nasal spray (2 sprays per nostril twice daily), or both agents together (same dosage). All three groups had statistically significant $(p<0.01)$ improvement from baseline in TNSS after 2 weeks' treatment, but the improvement was significant $(\mathrm{p}<0.05)$ with the combination regimen $(38 \%)$ versus either agent alone (azelastine: 25\%; fluticasone: $27 \%$ ) (Ratner and Sacks 2007).

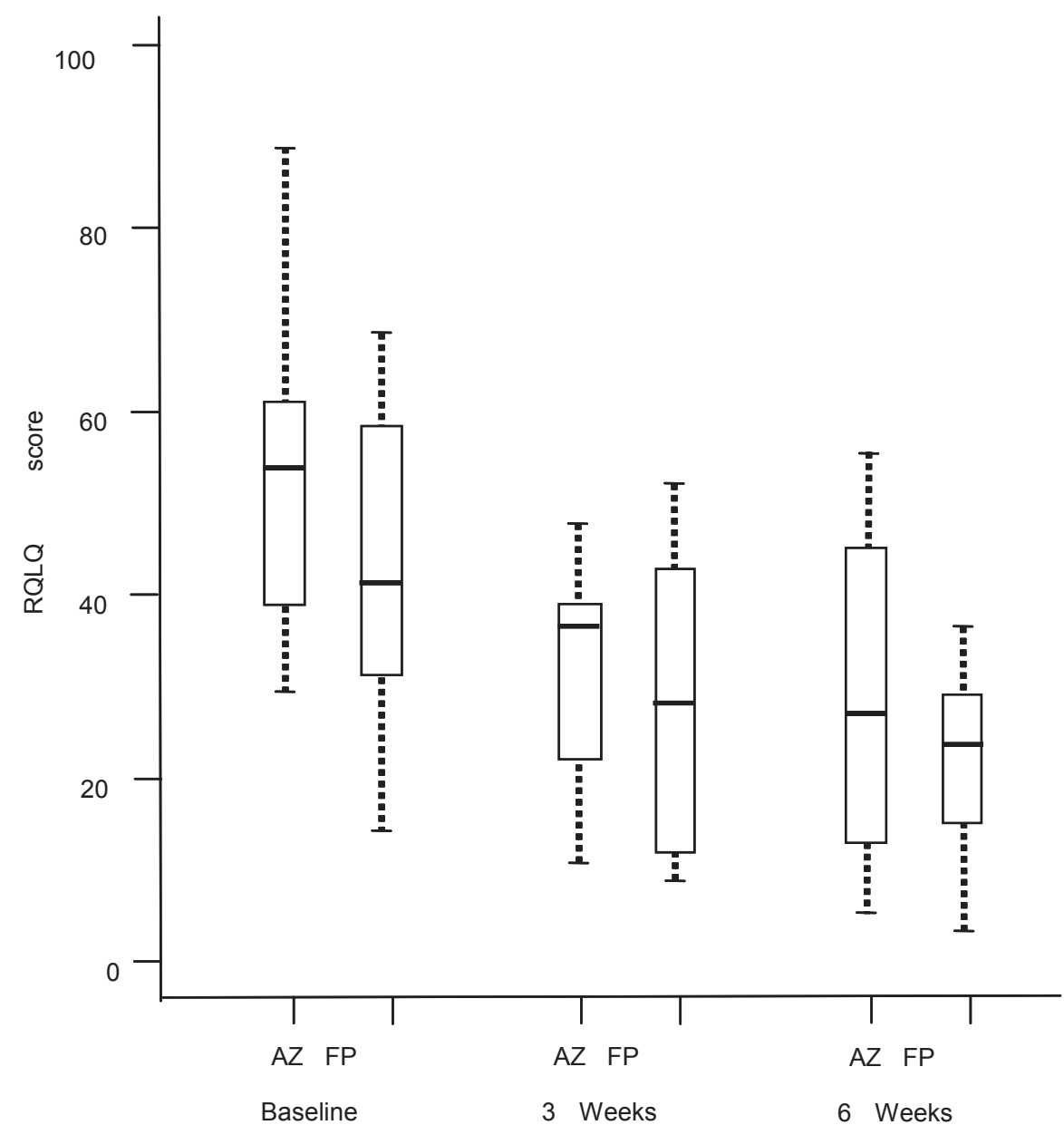

Figure 3 Effect of azelastine nasal spray or fluticasone propionate nasal spray on Rhinitis Quality of Life Questionnaire (RQLQ) scores in geriatric patients with either allergic or non-allergic rhinitis. Reprinted with permission from Behncke VB,Alemar GO, Kaufman DA, et al 2006. Azelastine nasal spray and fluticasone nasal spray in the treatment of geriatric patients with rhinitis. J Allergy Clin Immunol, I 17:263. Copyright @ 2006 Elsevier.

Abbreviations: AZ, azelastine; FP, fluticasone.

Therapeutics and Clinical Risk Management 2008:4(5) 


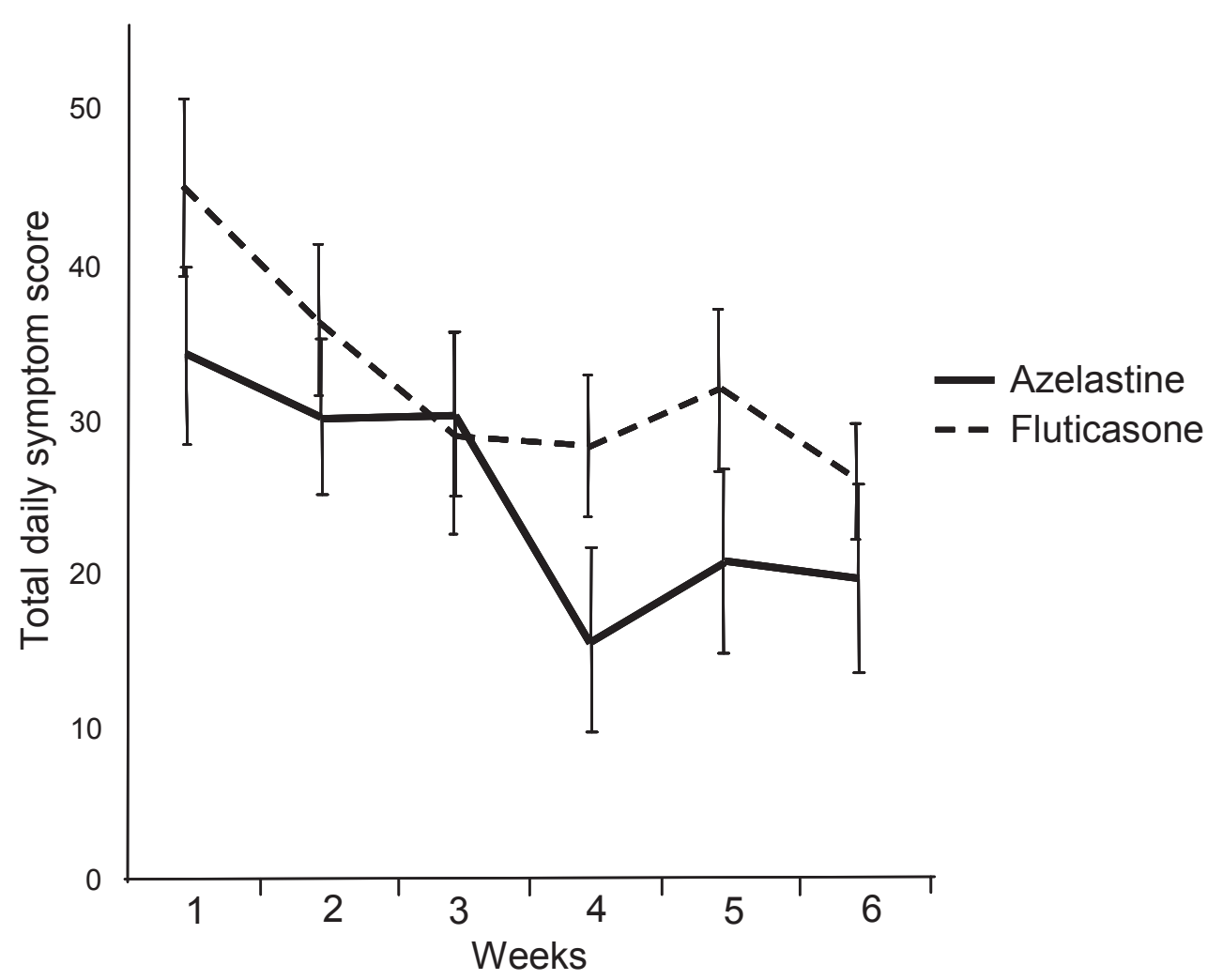

Figure 4 Effect of azelastine nasal spray or fluticasone propionate nasal spray on Total Daily Symptom Score (TDSS) in geriatric patients with either allergic or non-allergic rhinitis. Reprinted with permission from Behncke VB, Alemar GO, Kaufman DA, et al 2006. Azelastine nasal spray and fluticasone nasal spray in the treatment of geriatric patients with rhinitis. J Allergy Clin Immunol, I 17:263. Copyright (C) 2006 Elsevier.

\section{Comparisons with oral antihistamines}

Well-controlled studies in patients with rhinitis have shown that azelastine nasal spray demonstrates superior efficacy and a more rapid onset of action compared to oral antihistamines (McNeely and Wiseman 1998; Corren et al 2005; Berger et al 2006; Horak et al 2006; Meltzer and Sacks 2006; Sher and Sacks 2006). Azelastine is a potent drug and has been shown to be effective in patients suffering from rhinitis who have not responded to previous oral antihistamine therapy (Berger and White 2003; LaForce et al 2004). Additionally, it significantly reduces nasal congestion (Herman et al 1997), a particularly bothersome symptom for rhinitis sufferers. Unlike some of the earlier antihistamines, topical application of azelastine produces very low plasma concentrations of the drug which reduces the sedative potential. Indeed, compared with cetirizine and loratadine, azelastine actually increased alertness in patients with seasonal or perennial rhinitis (Spaeth et al 1996).

\section{Azelastine versus desloratadine}

Desloratadine is a new anti-histamine tablet. In contrast to antihistamines of earlier generations, these drugs are thought to noticeably reduce nasal congestion (McClellan and Jarvis
2001; Horak et al 2002b; Horak et al 2003), are non-sedating and do not cause cardiac side-effects. A recently published study was the first to assess the efficacy and onset of action of azelastine nasal spray (one spray per nostril) compared to desloratadine tablets $(5 \mathrm{mg}$ ) in patients with SAR (Horak et al 2006). Results showed that azelastine nasal spray was significantly better than desloratadine tablets in reducing the symptoms of SAR including 'nasal congestion' induced by allergen challenge in the Vienna Challenge Chamber (VCC). Both azelastine nasal spray and desloratadine tablets significantly $(\mathrm{p}<0.001)$ reduced the Major Nasal Symptom Score (MNSS; defined as the sum of scores of sneezing, rhinorrhea and nasal itching) compared to placebo (Figure 5) (Horak et al 2006), with azelastine significantly $(p=0.005)$ superior to desloratadine in this regard (Figure 5). In addition, the onset of action of azelastine nasal spray was $15 \mathrm{~min}$. compared with $150 \mathrm{~min}$. for desloratadine tablets. Regarding desloratadine tablets, the onset of action of $150 \mathrm{~min}$ reported by Horak et al (2006) was notably longer than that previously described (Horak et al 2002a). This may have been due to the encapsulation of desloratadine tablets for the purpose of blinding. 


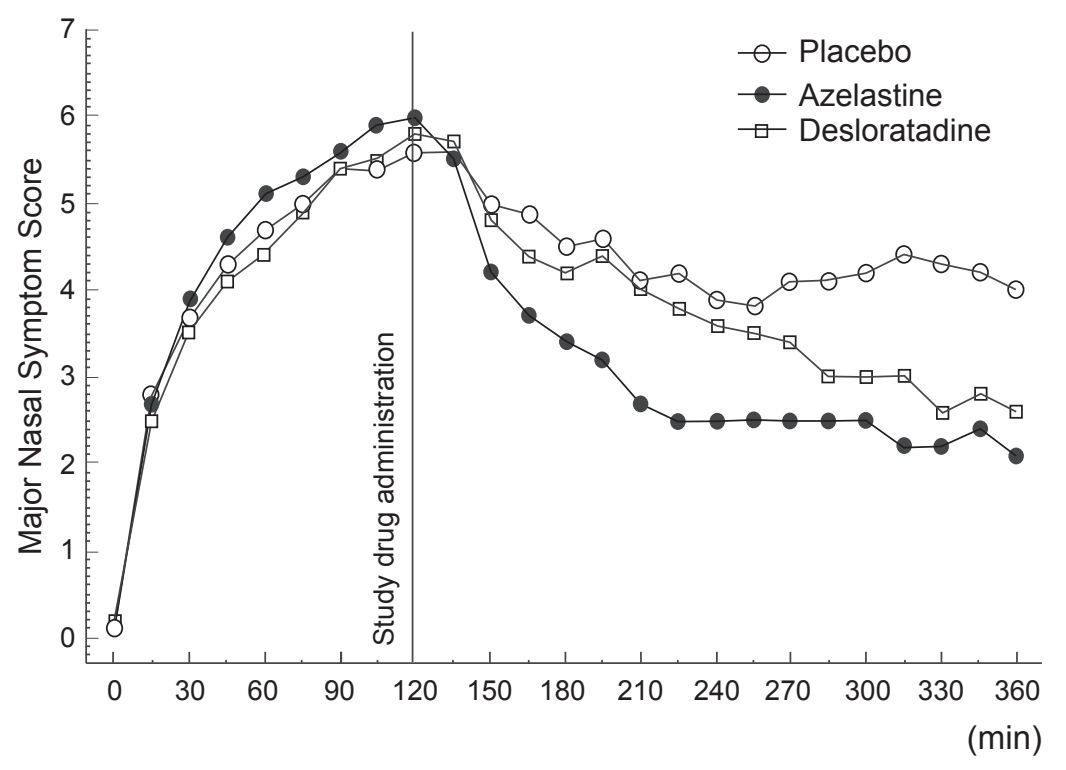

Figure 5 Major nasal symptom scores averaged over treatment and time for the per protocol population after administration of azelastine (I spray per nostril), desloratadine $(5 \mathrm{mg})$, or placebo in patients with SAR. Reprinted with permission from Horak F, Zieglmayer UP, Zidglmayer R, et al 2006. Azelastine nasal spray and desloratadine tablets in pollen-induced seasonal allergic rhinitis: a pharmacodynamic study of onset of action and efficacy. Curr Med Res Opion, 22:I5I-7. Copyright @ 2006 LibraPharm.

The mean 4- to 6-hour change in TNSS, which comprised a score for nasal congestion, were consistent with those for MNSS. The largest improvement with azelastine was observed for nasal itching followed by sneezing, rhinorrhea and nasal congestion (Figure 6) (Horak et al 2006). In fact, azelastine nasal spray was superior to desloratadine tablets at alleviating nasal congestion when comparing absolute scores at the end of the challenge. This result was unexpected since to date, antihistamines have been found to have little decongestant activity, whereas reduction of nasal congestion is one of the main clinical advantages of third-generation anti-histamines (Horak and Stübner 2002; Murdoch et al 2003). Significant decongestant activity has previously been reported for azelastine nasal spray, but only at the higher dosage of 2 sprays per nostril (Thomas et al 1992). Therefore, these results suggest that azelastine at a dosage of 1 spray per nostril is just as effective as 2 sprays. However, one should be reminded that the improvement in nasal congestion following azelastine therapy is a subjective one, and further objective studies, measuring nasal flow or nasal resistance, are required to confirm these findings.

\section{Azelastine versus cetirizine}

Cetirizine hydrochloride is an oral second-generation antihistamine indicated for the treatment of SAR and PR. It also has demonstrated inhibitory effects on other mediators of inflammation including leukotrienes (Cheria-Sammari et al 1995), prostaglandins (Charlesworth et al 1989),
ICAM-1 expression, and eosinophil chemotaxis (Ciprandi et al 1995). The first Azelastine Cetirizine Trial (ACT 1) carried out in the autumn of 2004, examined the effectiveness and tolerability of azelastine ( 2 sprays per nostril) and cetirizine tablets (10 mg once daily) in 307 patients with moderate to severe SAR (Corren et al 2005). During the 2-week double-blind treatment period, azelastine nasal spray significantly $(\mathrm{p}=0.02)$ improved the overall TNSS compared with cetirizine. All four symptom components of the TNSS were improved after azelastine therapy, with a significantly greater improvement versus cetirizine for rhinorrhea $(p=0.003)$. Differences in the TNSS between azelastine nasal spray and cetirizine were sustained throughout the study period and became more evident as the study progressed, with statistically significant differences favoring azelastine nasal spray on study days 8 through 14 . In addition, compared with cetirizine, azelastine nasal spray significantly ( $\mathrm{p}=0.049$ ) improved patients' HRQoL as assessed by the RQLQ (Corren et al 2005).

More recently, two 2-week, double-blind, multi-center studies were conducted which compared the efficacy and safety of azelastine nasal spray ( 2 sprays/nostril twice daily) with oral cetirizine (10 mg daily) in the treatment of patients with moderate to severe SAR (Sher and Sacks 2006). A combined analysis of results showed that azelastine nasal spray significantly improved the TNSS $(\mathrm{p}<0.001)$ and each of the four individual symptoms of the TNSS ( $\mathrm{p} \leq 0.01$ ) compared with cetirizine. Patients in the azelastine spray group experienced 


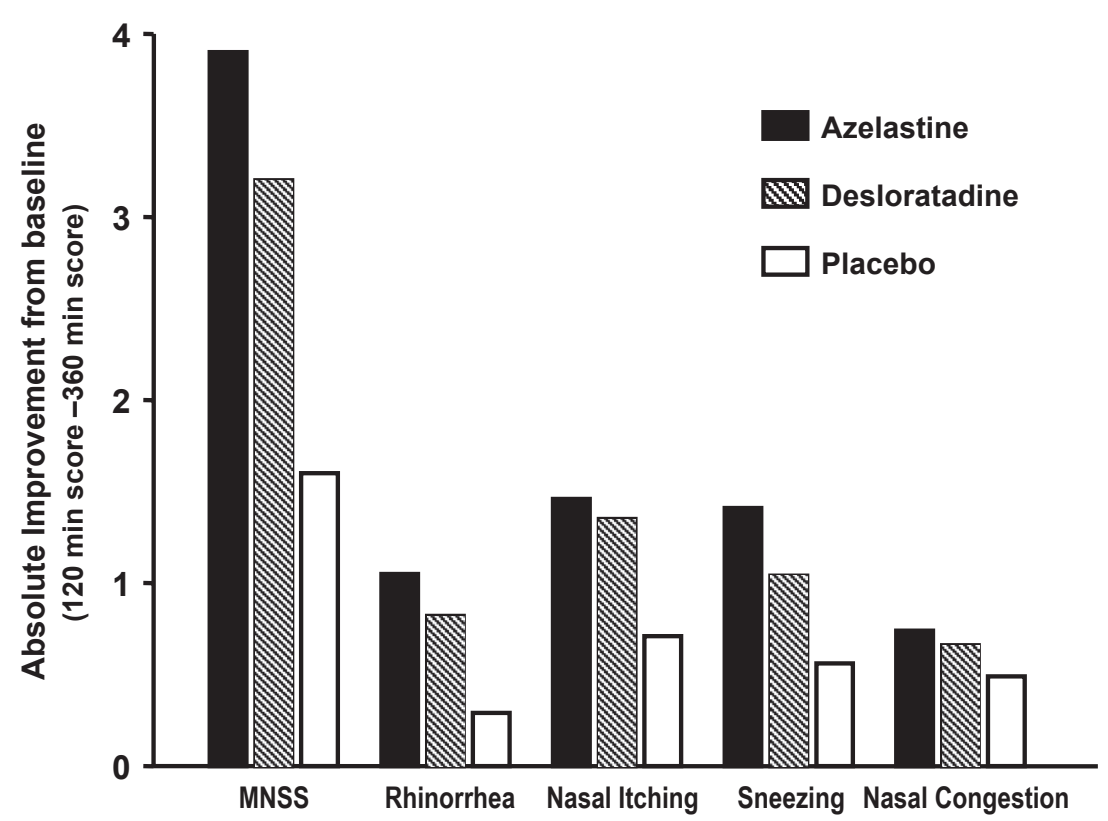

Figure 6 Major nasal symptom and mean nasal symptom scores after administration of azelastine nasal spray (I spray per nostril), desloratadine (5 mg) or placebo in patients with SAR: absolute changes of last value ( 6 hours after the start of challenge) compared to predose (ie, 2 hours after the start of the challenge). Reprinted with permission from Horak F, Zieglmayer UP, Zidglmayer R, et al 2006. Azelastine nasal spray and desloratadine tablets in pollen-induced seasonal allergic rhinitis: a pharmacodynamic study of onset of action and efficacy. Curr Med Res Opion, 22:15I-7. Copyright (C) 2006 LibraPharm.

an improvement in TNSS of $32.5 \%$ compared with $24.6 \%$ for those patients taking oral cetirizine. The most common side effect reported by patients in the azelastine group was bitter taste (5.7\%). Somnolence was reported by $1.5 \%$ of patients taking cetirizine (Sher and Sacks 2006).

In addition to nasal symptoms, patients with SAR can experience impairment in HRQoL. Two 2-week, double-blind, multicenter studies were conducted during autumn 2004 and spring 2005 comparing the improvement with azelastine nasal spray (2 sprays per nostril twice daily) versus cetirizine ( $10 \mathrm{mg}$ daily) on symptoms and HRQoL in SAR patients (Meltzer and Sacks 2006). Results from these studies revealed that azelastine nasal spray improved the overall RQLQ score to a significantly $(\mathrm{p}<0.05)$ greater degree than cetirizine tablets. When results from both studies were pooled, the combined analysis confirmed the significant superiority of azelastine spray both in terms of the overall RQLQ score $(p<0.001)$ as well as each RQLQ domain $(\mathrm{p}<0.03)$ including the nasal symptoms domain $(\mathrm{p}<0.001)$. More patients in the azelastine nasal spray group experienced a clinically important improvement from baseline in HRQoL (ie, $\geq 2$ units on the $0-6$ rating scale) compared with patients in the cetirizine group (35\% vs $20 \%$ respectively) (Meltzer and Sacks 2006).

Berger et al (2006) also showed that azelastine nasal spray ( 2 sprays per nostril) and oral cetirizine (10 $\mathrm{mg}$ once daily) effectively treated nasal symptoms in patients with SAR
( $\mathrm{n}=360$ ). Rapid relief of rhinitis symptoms was evident in both groups at the first evaluation after initial administration and continued during the 14 study days, with the azelastine patients showing the greatest degree of improvement during the second week of treatment. Improvements in the TNSS and individual symptoms favored azelastine over cetirizine (Figure 7), with significant differences for nasal congestion $(p=0.049)$ and sneezing $(p=0.01)$. Azelastine nasal spray improved TNSS by a mean of $4.6(23.9 \%)$ compared with $3.9(19.6 \%)$ with cetirizine. The positive effect of azelastine nasal spray on congestion was observed despite the fact that the cetirizine group had the added benefit of daily use of a placebo saline spray. Azelastine nasal spray also significantly improved the RQLQ overall $(\mathrm{p}=0.002)$ and individual domain $(\mathrm{p} \leq 0.05)$ scores compared with cetirizine (Berger et al 2006). Although oral cetirizine significantly improved RQLQ scores, patients treated with azelastine nasal spray reported additional statistically significant improvement beyond that reported with cetirizine for each individual RQLQ domain including activities, sleep, non-nose/non-eye symptoms, practical problems, nasal symptoms, eye symptoms, and emotions (Figure 8). Although it is often assumed that patients prefer oral medications to sprays in both the ACT I and ACTII trials, patients reported superior improvements in QoL variables with azelastine nasal spray compared with oral cetirizine (Corren et al 2005). 


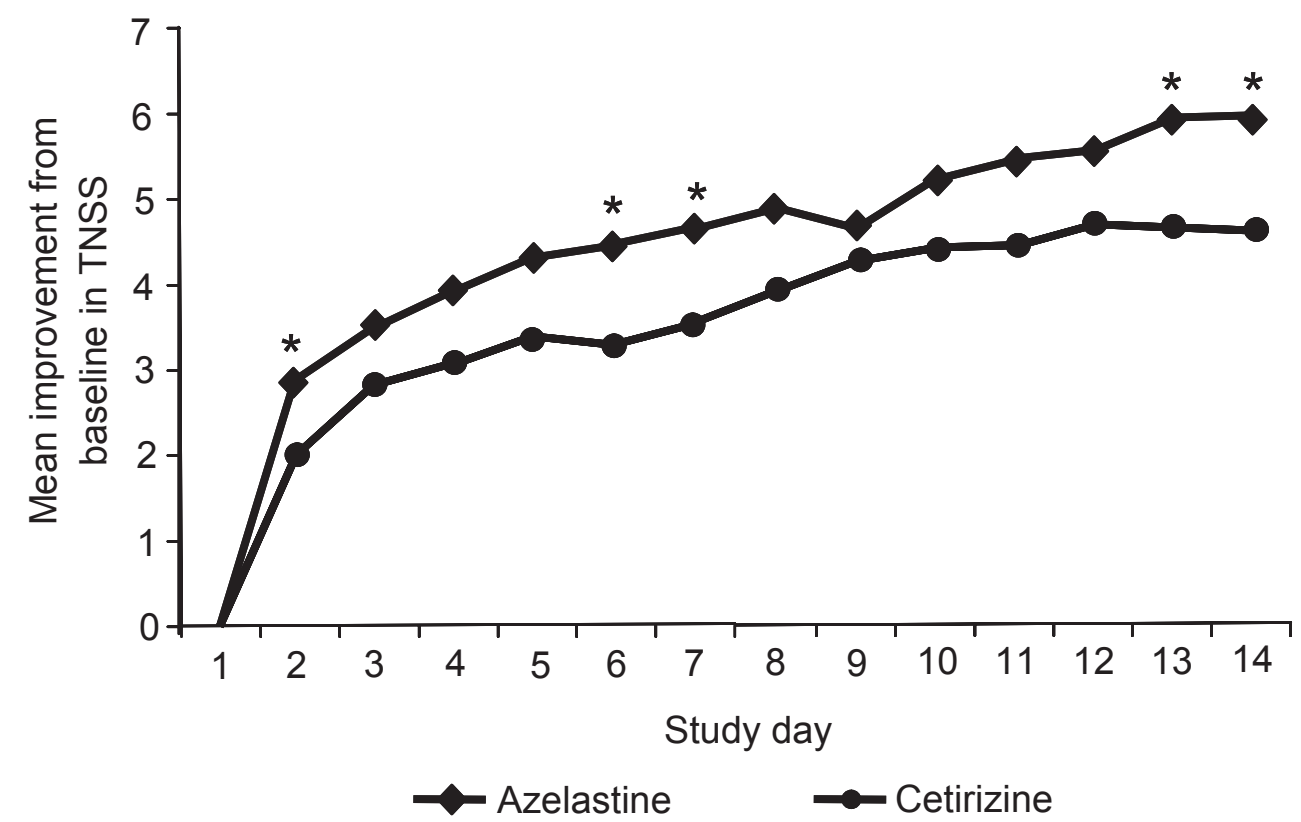

Figure 7 Mean daily improvements from baseline to day 14 in combined morning and evening I2-hour reflective total nasal symptom scores (TNSSs). * $<0.05$ versus cetirizine. Reprinted with permission from BergerW, Hampel F, Bernstein J, et al 2006. Impact of azelastine nasal spray on symptoms and quality of life compared with cetirizine oral tablets in patients with seasonal allergic rhinitis. Ann Allergy Asthma Immunol, 97:375-8I. Copyright @ 2006 American College of Allergy, Asthma and Immunology.

Azelastine nasal spray and cetirizine were well tolerated in this study (Berger et al 2006). Relatively high incidences of somnolence and bitter taste have been previously reported in early trials with azelastine nasal spray (Meltzer et al 1994; Storms et al 1994; Weiler et al 1994; LaForce et al 2004; Ratner and Sacks 2007). However, subsequent trials in patients with VMR (Banov and Liberman 2001) and postmarketing studies in patients who remained symptomatic after treatment with loratadine (Berger and White 2003) or fexofenadine (LaForce 1999) reported somnolence rates with azelastine nasal spray that were similar to those with placebo.

\section{Non-responders}

As many as $20 \%$ of all AR patients do not respond to oral $\mathrm{H}_{1}$ blockers at all (Berger and White 2003). Two studies assessed the efficacy of azelastine in patients with moderate-to-severe SAR who had an unsatisfactory response to oral second generation antihistamines (Berger and White 2003; LaForce et al 2004). The first study comprised 435 patients who had a sub-optimal response to loratadine and showed that both azelastine monotherapy and azelastine plus loratadine significantly $(\mathrm{p}<0.001)$ improved total symptoms compared with placebo (Berger and White 2003). The second study comprised 334 patients who had failed to response to 1 week treatment with fexofenadine. Similar results were obtained, in that patients in both the azelastine and combination groups showed significant $(\mathrm{p}<0.01)$ improvement in their symptoms compared with placebo.

\section{Azelastine versus other intranasal antihistamines}

\section{Azelastine versus levocabastine}

Levocabastine is a potent and selective histamine $\mathrm{H}_{1}$-receptor antagonist. Previous limited data indicated equivalent efficacy of levocabastine to that of oral loratadine, oral cetirizine or azelastine nasal spray (Noble and McTavish 1995). More recently, the efficacy and tolerability of azelastine nasal spray (1.12 mg, 2 sprays twice daily) was shown to be statistically superior to that of topical intranasal levocabastine $(0.4 \mathrm{mg}, 2$ sprays twice daily) in a 4-week, double-blind, parallel-group study in 180 patients (Falser et al 2001). Results showed that azelastine was significantly ( $\mathrm{p}<0.001$ ) superior at reducing both morning and evening nasal symptoms compared to levocabastine, and was judged to be significantly ( $\mathrm{p}<0.007$ ) more efficacious in a global evaluation by the investigator. Global efficacy was judged by physicians as either 'very good' or 'good' for $90 \%$ of azelastine patients compared to $74 \%$ of the levocabastine group; moreover, $92 \%$ of azelastine patients judged the treatment 


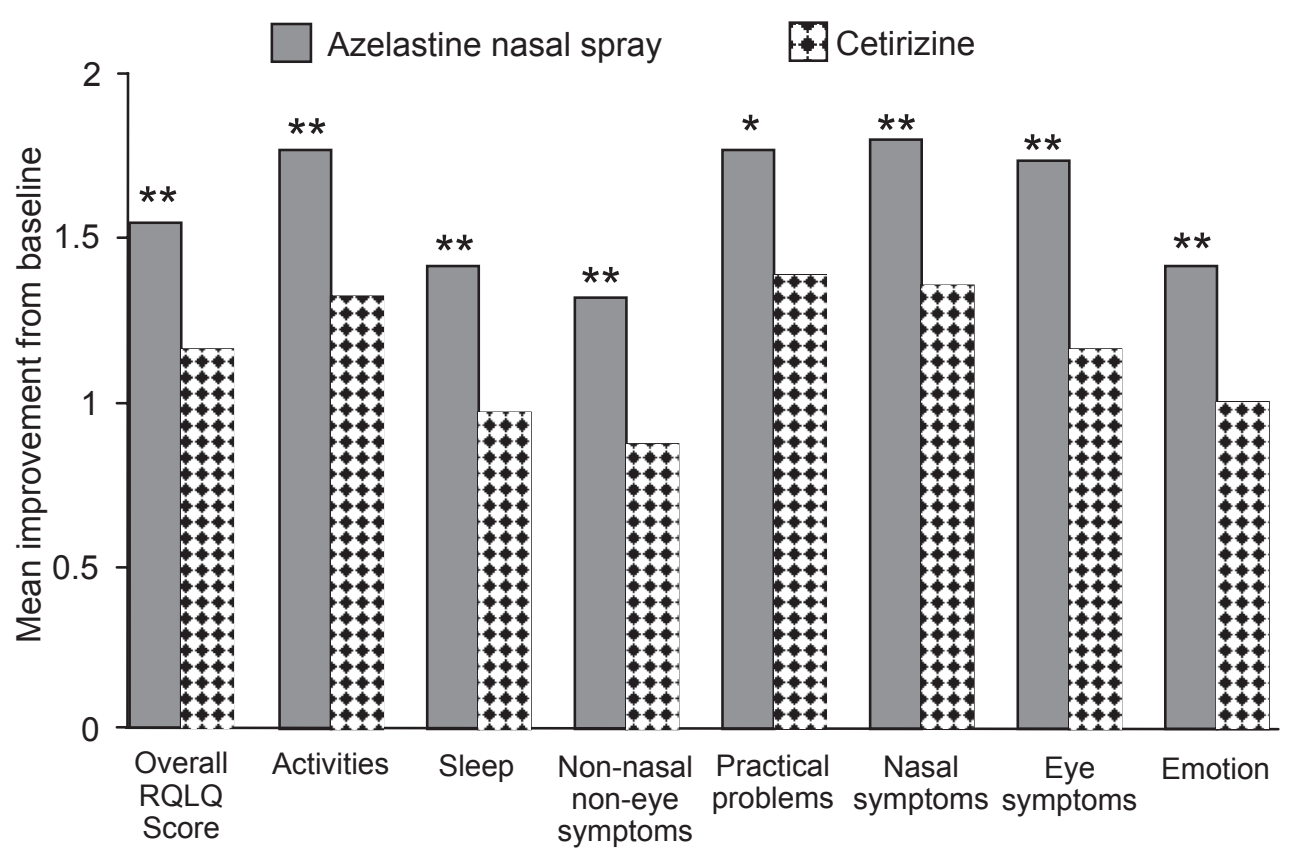

Figure 8 Mean improvement from baseline to day 14 in overall Rhinoconjunctivitis Quality of Life Questionnaire (RQLQ) score and individual RQLQ domain scores (intention-totreat population). ${ }^{*} \mathrm{p} \leq 0.05$ vs cetirizine; ${ }^{* *} \mathrm{p}<0.0 \mathrm{I}$ vs cetirizine. Reprinted with permission from Berger W, Hampel F, Bernstein J, et al 2006 . Impact of azelastine nasal spray on symptoms and quality of life compared with cetirizine oral tablets in patients with seasonal allergic rhinitis. Ann Allergy Asthma Immunol, 97:375-8I. Copyright @ 2006 American College of Allergy, Asthma and Immunology.

as either 'good' or 'very good' compared with just $76 \%$ of levocabastine patients (Falser et al 2001).

\section{Safety and tolerability}

The advantages of intranasal delivery include lower risk of systemic side effects and drug interactions (Salib and Howarth 2003). In controlled studies, azelastine nasal spray was well-tolerated for treatment durations up to 4 weeks in both adults and children ( $\geq 12$ years) (Storms et al 1994; Meltzer et al 1994; Ratner et al 1994; Weiler et al 1994; LaForce et al 1996). Bitter taste, headache, somnolence and nasal burning were the most frequently reported adverse events, but most of these were mild or moderate in nature. These studies reported a greater incidence of somnolence compared with placebo $(11.5 \%$ vs $5.4 \%, \mathrm{p}<0.05)$. However, the incidence of somnolence between azelastine- and placebo-treated patients $(3.2 \%$ vs $1.0 \%)$ did not differ in VMR studies (Banov and Liberman 2001). Post-marketing surveillance studies also reported a similar degree of somnolence (approx 2\%) in both azelastine and placebo groups (Berger and White 2003; LaForce et al 2004; Corren et al 2005; Berger et al 2006). The lower incidence of azelastine-related adverse events in later trials is most likely due to correct dosing technique, when the drug is administered without tipping back the head or deeply inhaling the spray, both of which would increase systemic absorption and could result in bitter taste and somnolence. As the incidence of somnolence whilst using azelastine nasal spray has been reported to be greater than placebo in certain studies, US prescribing recommendations warn against concurrent use of alcohol and/or other CNS suppressants. However, to date no studies have been designed to assess specifically the effects of azelastine nasal spray on the CNS in humans.

\section{Disclosures}

The author has no conflicts of interest to report.

\section{Abbreviations}

ACT 1, first Azelastine Cetirizine Trial; AR, allergic rhinitis; ARIA, allergic rhinitis and its impact on asthma; EEC, environmental exposure chamber; GM-CSF, granulocyte macrophage-colony stimulating factor; HRQoL, health-related quality of life; ICAM-1, intercellular adhesion molecule-1; IL, interleukin; LT, leukotriene; MNSS, major nasal symptom score; NNT, number needed to treat; PR, perennial rhinitis; QoL, quality of life; RQLQ, Rhinoconjunctivitis Quality of Life Questionnaire; SAR, seasonal allergic rhinitis; TNF $\alpha$, tumor necrosis factor alpha; 
TNSS, total nasal symptom score; TVRSS, Total VMR Symptom Scale; VCC, Vienna Challenge Chamber; VMR, vasomotor rhinitis.

\section{References}

Al Suleimani YM, Walker MJA. 2007. Allergic rhinitis and its pharmacology. Pharmacol Ther, 114:233-60.

Anon. 2001. Physician survey sponsored by the American College of Allergy, Asthma and Immunology. Rochester (NY): Harris Interactive Inc, October 19-21.

Anon. 2006. Allergies in America: a landmark survey of nasal allergy sufferers. HealthSTAR Communications, Inc. Sponsored by Altana Pharma US, Inc. March 1.

Banov CH, Liberman P. 2001. Efficacy of azelastine nasal spray in the treatment of vasomotor (perennial nonallergic) rhinitis. Ann Allergy Asthma Immunol, 86:28-35.

Baumgarten CR, Petzold U, Dokic D, et al. 1994. Modification of allergeninduced symptoms and mediator release by intranasal azelastine. J Pharmacol Ther, 3:43-51.

Beck G, Mansur A, Afzal M, et al. 2000. Effect of azelastine nasal spray on mediators of inflammation in patients with seasonal allergic rhinitis (SAR). American Academy of Allergy, Asthma and Immunology 56th Annual Meeting, San Diego (CA); March 3-8.

Behncke VB, Alemar GO, Kaufman DA, et al. 2006. Azelastine nasal spray and fluticasone nasal spray in the treatment of geriatric patients with rhinitis. J Allergy Clin Immunol, 117:263

Berger W, Hampel F, Bernstein J, et al. 2006. Impact of azelastine nasal spray on symptoms and quality of life compared with cetirizine oral tablets in patients with seasonal allergic rhinitis. Ann Allergy Asthma Immunol, 97:375-81.

Berger WE, White MV. 2003. Efficacy of azelastine nasal spray in patients with an unsatisfactory response to loratadine. Ann Allergy Asthma Immunol, 91:205-11.

Berkowitz TB, Bernstein DI, LaForce C, et al. 1999. Onset of action of mometasone furoate nasal spray (NASONEX) in seasonal allergic rhinitis. Allergy, 54:64-9.

Bernstein JA. 2007. Azelastine hydrochloride: a review of pharmacology, pharmacokinetics, clinical efficacy and tolerability. Curr Med Res Opin, 23:2441-52.

Bielory L, Ambrosio P. 2002. Conjunctivitis and allergic eye diseases. In: Kaliner MA, editor. Current Reviews of Rhinitis. Philadelphia: Current Medicine, Inc. pp. 115-22.

Bousquet J, van Cauwenberge PB, Khaltaev N, et al. 2001. Allergic rhinitis and its impact on asthma: ARIA workshop report. J Allergy Clin Immunol, 108:S147-S334.

Busse W, Randley B, Sedgwick J, et al. 1989. The effect of azelastine on neutrophil and eosinophil generation of superoxide. J Allergy Clin Immunol, 83:400-5.

Casale TB. 1989. The interaction of azelastine with human lung histamine H1, beta, and muscarinic receptor binding sites. J Allergy Clin Immunol, 83:771-6.

Charlesworth EN, Kagey-Sobotka A, Norman PS, et al. 1989. Effect of cetirizine on mast cell-mediator release and cellular traffic during the cutaneous late-phase reaction. J Allergy Clin Immunol, 83:905-12.

Cheria-Sammari S, Aloui R, Gormand B, et al. 1995. Leukotriene B4 production by blood neutrophils in allergic rhinitis: effects of cetirizine. Clin Exp Allergy, 25:729-36.

Ciprandi G, Buscaglia S, Pesce G, et al. 1995. Cetirizine reduces inflammatory cell recruitment and ICAM-1 (or CD54) expression on conjunctival epithelium in both early-and late-phase reactions after allergen-specific challenge. J Allergy Clin Immunol, 95:612-21.

Ciprandi G, Pronzato C, Passalacqua G, et al. 1996. Topical azelastine reduces eosinophil activation and intercellular adhesion molecule-I expression on nasal epithelial cells: an anti-allergic activity. J Allergy Clin Immunol, 98:1088-96.
Ciprandi G, Ricca V, Passalaqua G, et al. 1997. Seasonal rhinitis and azelastine: long- or short-term treatment? J Allergy Clin Immunol, 99:301-7.

Corren J, Storms W, Bernstein J, et al. 2005. Effectiveness of azelastine nasal spray compared with oral cetirizine in patients with seasonal allergic rhinitis. Clin Ther, 27:543-53.

Davies RJ, Bagnall AC, McCabe RN, et al. 1996. Antihistamines: topical vs oral administration. Clin Exp Allergy, 26:S11-S17.

Devyani L, Corey JP. 2004. Vasomotor rhinitis update. Curr Opin Otolaryngol Head Neck Surg, 12:243-247.

Dykewicz MS, Fineman S, Skoner DP, et al. 1998. Diagnosis and management of rhinitis: complete guidelines of the Joint ask Force on Practice Parameters in Allergy, Asthma and Immunology. Ann Allergy Asthma Immunol, 81:478-518.

Economides A, Kaliner MA. 2002. Allergic rhinitis. In: Kaliner MA, ed. Current Reviews of Rhinitis. Philadelphia: Current Medicine, Inc. pp. 35-51.

Falser N, Wober W, Rahlfs VW, et al. 2001. Comparative efficacy and safety of azelastine and levocabastine nasal sprays in patients with seasonal allergic rhinitis. Arzeimittelforschung, 51:387-93.

Golden MP, Gleason MM, Togias A. 2006. Cysteinyl leukotrienes: multi-functional mediators in allergic rhinitis. Clin Exp Allergy, 36:689-703

Golden S, Teets SJ, Lehman EB, et al. 2000. Effect of topical nasal azelastine on the symptoms of rhinitis, sleep and daytime somnolence in perennial allergic rhinitis. Ann Allergy Asthma Immunol, 85:53-7.

Greiff L, Andersson M, Svensson C, et al. 1997. Topical azelastine has a 12-hour duration of action as assessed by histamine challenge-induced exudation of alpha 2-macroglobulin into human nasal airways. Clin Exp Allergy, 27:438-44.

Hamasaki Y, Shafigeh M, Yamamoto S, et al. 1996. Inhibition of leukotriene synthesis by azelastine. Ann Allergy Asthma Immunol, 76:469-75.

Herman D, Garay R, Legal M. 1997. A randomized double-blind placebo controlled study of azelastine nasal spray in children with perennial rhinitis. Int J Pediatr Otorhinolaryngol, 39:1-8.

Hide I. Toriu N, Nuibe T, et al. 1997. Suppression of TNF- $\alpha$ secretion by azelastine in a rat mast (RBL-2H3) cell line. J Immunol, 159:2932-40.

Horak F, Jager S, Toth J, et al. 1994. Azelastine in pollen-induced allergic rhinitis - a pharmacodynamic study of onset of action and efficacy. Drug Invest, 7:34-40.

Horak F, Stübner P, Zieglmayer R, et al. 2003. Comparison of the effect of Desloratadine $5 \mathrm{mg}$ daily and placebo on nasal airflow and seasonal allergic rhinitis symptoms induced by grass pollen exposure. Allergy, 58:481-5.

Horak F, Stübner P. 2002. Decongestant activity of desloratadine in controlled-allergen-exposure trials. Clin Drug Invest, 22(Suppl 2):13-20

Horak F, Stübner UP, Zieglmayer R, et al. 2002a. Effect of desloratadine versus placebo on nasal airflow and subjective measures of nasal obstruction in patients with grass pollen-induced allergic rhinitis in an allergen-exposure unit. J Allergy Clin Immunol, 109:956-61.

Horak F, Stübner UP, Zieglmayer R, et al. 2002b. Effect of desloratadine versus placebo on nasal airflow and subjective measures of nasal obstruction in subjects with grass pollen-induced allergic rhinitis in an allergen-exposure unit. J Allergy Clin. Immunol, 109:956-61.

Horak F, Zieglmayer UP, Zieglmayer R, et al. 2006. Azelastine nasal spray and Desloratadine tablets in pollen-induced seasonal allergic rhinitis: a pharmacodynamic study of onset of action and efficacy. Curr Med Res Opion, 22:151-7.

Howarth PH. 1997. Mediators of nasal blockage in allergic rhinitis. Allergy, 52(Suppl 40):12-8.

Ito H, Nakamura Y, Takagi S, et al. 1998. Effects of azelastine on the level of serum interluekin-4 and soluble CD23 antigen in the treatment of nasal allergy. Arzneim-Forsch, 48:1143-7.

Juniper EF. 1997. Measuring health-related quality of life in rhinitis. J Allergy Clin Immunol, 99:S742-S9. 
Kempuraj D, Huang M, Kandere K, et al. 2002. Azelastine is more potent than olopatadine in inhibiting interleukin-6 and tryptase release from human umbilical cord blood derived cultured mast cells. Ann Allergy Asthma Immunol, 88:501-6.

LaForce C, Dockhorn RJ, Prenner BM, et al. 1996. Safety and efficacy of azelastine nasal spray (Astelin NS) for seasonal allergic rhinitis. Ann Allergy Asthma Immunol, 76:181-8.

LaForce C. 1999. Use of nasal steroids in managing allergic rhinitis. J Allergy Clin Immunol, 103:S388-S94.

LaForce CF, Corren J, Wheeler WJ, et al. 2004. Efficacy of azelastine nasal spray in seasonal allergic rhinitis patients who remain symptomatic after treatment with fexofenadine. Ann Allergy Asthma Immunol, 93:154-9.

Lee C, Corren J. 2007. Review of Azelastine nasal spray in the treatment of allergic and non-allergic rhinitis. Expert Opin Pharmacother, 8:701-9.

Lee T, Pickard S. 2007. Meta-analysis of azelastine nasal spray for the treatment of allergic rhinitis. Pharmcotherapy, 27:852-9.

Liberman P, Kaliner MA, Wheeler WJ. 2005. Open-label evaluation of azelastine nasal spray in patients with seasonal allergic rhinitis and nonallergic vasomotor rhinitis. Curr Med Res Opin, 21:611-8.

Lumry W, Prenner B, Corren J, et al. 2007. Efficacy and safety of azelastine nasal spray at a dose of 1 spray per nostril twice daily. Ann Allergy Asthma Immunol, 99:267-72.

Mahr TA, Sheth K. 2005. Update on allergic rhinitis. Pediatr Rev, 26:284-9.

Matsuo S, Takayama S. 1998. Influence of the anti-allergic agent, azelastine, on tumor necrosis factor-alpha (TNF- $\alpha$ ) secretion from cultured mouse mast cells. In Vivo, 12:481-4.

McClellan K, Jarvis B. 2001. Desloratadine. Drugs, 61:789-96.

McNeely W, Wiseman LR. 1998. Intranasal azelastine - a review of its efficacy in the management of allergic rhinitis. Drugs, 56:91-114.

McTavish D, Sorkin EM. 1989. Azelastine - A review of its pharmacodynamic and pharmacokinetic properties, and therapeutic Potential. Drugs, 38:778-800.

Meltzer EO, Sacks H. 2006. Azelastine nasal spray significantly improves health related quality of life compared to cetirizine tablets in patients with seasonal allergic rhinitis (SAR). J Allergy Clin Immunol, 117:S324.

Meltzer EO, Weiler JM, Dockhorn RJ, et al. 1994. Azelastine nasal spray in the management of seasonal allergic rhinitis. Ann Allergy, 72:354-9.

Morita M. Ohshima Y, Akutagawa H, et al. 1993. Inhibitory effects of azelastine hydrochloride on $\mathrm{CA} 2^{+}$influx, actin polymerization and release of eosinophils cationic protein of an eosinophilic leukaemia cell line EoL-1. Curr Med Res Opin, 13:163-74.

Murdoch D, Goa KL, Keam SJ. 2003. Desloratadine - an update of its efficacy in the management of allergic disorders. Drugs, 63:2051-77.

Nakamura T, Nishizawa Y, Sato T, et al. 1988. Effect of azelastine on the intracellular $\mathrm{Ca}_{2}{ }^{+}$mobilization in guinea pig peritoneal macrophages. Eur J Pharmacol, 148:35-41.

Nieber K, Baumgarten C, Rathsack R, et al. 1993. Effect of azelastine on Substance $\mathrm{P}$ content in bronchoalveolar and nasal lavage fluids of patients with allergic asthma. Clin Exp Allergy, 23:69-71.

Nielsen LP, Dahl R. 2003. Comparison of intranasal corticosteroids and antihistamines in allergic rhinitis. Am J Respir Med, 2:55-65.

Noble S, McTavish D. 1995. Levocabastine. An update of its pharmacology, clinical efficacy and tolerability in the topical treatment of allergic rhinitis and conjunctivitis. Drugs, 50:1032-49.

Patel P, D'Andrea C, Sacks HJ. 2007. Onset of action of azelastine nasal spray compared with mometasone nasal spray and placebo in subjects with seasonal allergic rhinitis evaluated in an environmental exposure chamber. Am J Rhinol, 21:499-503.
Physician Survey. 2001. Physician Survey sponsored by the American College of Allergy, Asthma and Immunology. Harris Interactive, Inc., Rochester, NY; October 19-29.

Portnoy JM, Van Osdol T, Williams PB. 2004. Evidence-based strategies for treatment of allergic rhinitis. Curr Allergy Asthma Rep, 4:439-46.

Ratner P, Sacks H. 2007. Randomized, double-blind trial of azelastine nasal spray plus fluticasone nasal spray compared to either agent alone in patients with allergy to Texas Mountain Cedar. Ann Allergy Asthma Immunol, 98(Suppl 1):A20.

Ratner PH, Findlay SR, Hampel F, et al. 1994. A double-blind, controlled trial to assess the safety and efficacy of azelastine nasal spray in seasonal allergic rhinitis. J Allergy Clin Immunol, 94:818-25.

Ray NF, Baraniuk JN, Thamer M, et al. 1999. Direct expenditures for the treatment of allergic rhinoconjunctivitis in 1996, including the contributions of related airway illnesses. J Allergy Clin Immunol, 103:401-7.

Reed SD, Lee TA, McCrory DC. 2004. The economic burden of allergic rhinitis: a critical evaluation of the literature. Pharmacoeconomics, 22:345-61.

Salib JR, Howarth PH. 2003. Safety and tolerability profiles of intranasal antihistamines and intranasal corticosteroids in the treatment of allergic rhinitis. Drug Saf, 26:863-93.

Settipane RA, Settipane GA. 2002. Nonallergic rhinitis. In: Kaliner MA, (ed.) Current Reviews of Rhinitis. Philadelphia: Current Medicine, Inc. pp. 53-65.

Settipane RA. 2001. Demographics and epidemiology of allergic and nonallergic rhinitis. Allergy Asthma Proc, 22:185-9.

Sher E, Sacks H. 2006. Azelastine nasal spray compared to cetirizine in the treatment of patients with seasonal allergic rhinitis: a pooled analysis of two double-blind, multicenter studies. J Allergy Clin Immunol, 117:S319.

Shin MH, Baroody F, Proud D, et al. 1992. The effect of azelastine on the early allergic response. Clin Exp Allergy, 22:289-95.

Shinoda M, Watanabe N, Suko T, et al. 1997. Effects of anti-allergic drugs on substance P (SP) and vasoactive intestinal peptide (VIP) in nasal secretions Am J Rhinol, 11:237-41.

Spaeth J, Klimek L, Moesges R. 1996. Sedation in allergic rhinitis is caused by the condition and not by antihistamine treatment. Allergy, 51:893-906.

Storms WW, Pearlman DS, Chervinsky P, et al. 1994. Effectiveness of azelastine nasal solution in seasonal allergic rhinitis. ENT J, 73:382-9.

Thomas KE, Ollier S, Ferguson H, et al. 1992. The effect of intranasal azelastine, Rhinolast ${ }^{\circledR}$, on nasal airway obstruction and sneezing following provocation testing with histamine and allergen. Clin Exp Allergy, 22:642-7.

Umeki S. 1992. Effects of antiallergic drops on human neutrophil superoxide generating NADPH oxidase. Biochem Pharmacol, 43:1109-17.

Wang D, Smitz J, De Waele M, et al. 1997. Effect of topical applications of budesonide and azelastine on nasal symptoms, eosinophil count and mediator release in atopic patients after nasal allergen challenge during the pollen season. Int Arch Allergy Immunol, 114:185-92.

Weiler JM. Meltzer EO, Benson PM, et al. 1994. A dose-ranging study of the efficacy and safety of azelastine nasal spray in the treatment of seasonal allergic rhinitis with an acute model. J Allergy Clin Immunol, 94:972-80.

Weiner JM, Abramson MJ, Puy, RM. 1998. Intranasal corticosteroids versus oral H1-receptor antagonists in allergic rhinitis: systematic review of randomized controlled trials. $B M J, 317: 1624-9$.

Yoneda K, Yamamoto T, Ueta E, et al. 1997. Suppression by azelastine hydrochloride of NF- $\mathrm{KB}$ activation involved in generation of cytokines and nitric oxide. Jpn J Pharmacol, 73:145-53.

Zechel HJ, Brock N, Lenke D, et al. 1981. Pharmacological and toxicological properties of azelastine, a novel anti-allergic agent. Arzneim-Forsch, 31:1184-93. 